\title{
Publisher Correction: Tunnelling spectroscopy of gate-induced superconductivity in $\mathrm{MoS}_{2}$
}

Davide Costanzo, Haijing Zhang, Bojja Aditya Reddy, Helmuth Berger and Alberto F. Morpurgo (D)

Correction to: Nature Nanotechnology https://doi.org/10.1038/s41565-018-0122-2, published online 30 April 2018.

In the version of this Article originally published, an error during typesetting led to the curve in Fig. $2 \mathrm{a}$ being shifted to the right, and the curves in the inset of Fig. 2 a being displaced. The figure has now been corrected in all versions of the Article; the original and corrected Fig. $2 \mathrm{a}$ are shown below.
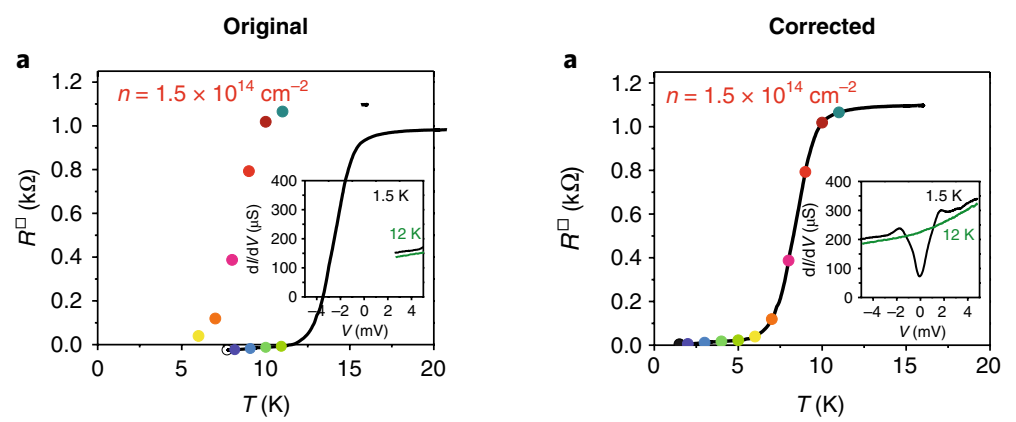

Fig. 2a | Original and corrected.

Published online: 17 May 2018

https://doi.org/10.1038/s41565-018-0159-2

\section{Publisher Correction: Quantum engineering of transistors based on 2D materials heterostructures}

Giuseppe lannaccone, Francesco Bonaccorso, Luigi Colombo and Gianluca Fiori

Correction to: Nature Nanotechnology https://doi.org/10.1038/s41565-018-0082-6, published online 6 March 2018.

In the version of this Perspective originally published, in the email address for the author Giuseppe Iannaccone, the surname was incorrectly given as "innaconne"; this has now been corrected in all versions of the Perspective. Also, an error in the production process led to Figs. 1, 2 and 3 being of low resolution; these have now been replaced with higher-quality versions. 